\title{
One pot synthesis of benzoxazoles, benzthiazoles and benzimidazoles from carboxylic acids using ionic liquids
}

\author{
Mohan Babu Maradolla, Sunil Kumar Allam, Amaravathi Mandha, and G. V. P. \\ Chandramouli*
}

Department of Chemistry, National Institute of Technology, Warangal (AP)-506021, India

E-mail:gvpc_2000@yahoo.co.in,mohanorg@yahoo.com

\begin{abstract}
Benzoxazoles, benzthiazoles and benzimidazoles can be rapidly and efficiently synthesized in excellent yields by condensing a variety of carboxylic acids with 2-aminophenol, 2aminothiophenol and 1,2-phenylenediamines under ambient conditions using the ionic liquid 1butyl 3-methyl imidazolium tetraflouroborate $\left[(\mathrm{bmim}) \mathrm{BF}_{4}\right]$ at higher temperatures.
\end{abstract}

Keywords: Ionic liquids, benzimidazoles, benzoxazoles, benzthiazoles, carboxylic acids

\section{Introduction}

2-Aryl benzoxazoles, benzthiazoles and benzimidazoles have received considerable attention in diverse areas of chemistry. ${ }^{1-5}$ These heterocycles exhibit pharmacological activities such as antiviral, ${ }^{6}$ antimicrobial, ${ }^{7}$ antifungal, ${ }^{8}$ antiparkinson, ${ }^{9}$ anticancer ${ }^{10}$ and antibiotic ${ }^{11}$ properties. They are also used as ligands for asymmetric transformations ${ }^{12}$. A number of methods have been reported for the synthesis of these heterocycles which include condensation of carboxylic acids ${ }^{13}$ and their derivatives like orthoesters, ${ }^{14-16}$ nitriles, ${ }^{17}$ amides, ${ }^{18}$ aldehydes ${ }^{19}$ and esters ${ }^{20}$ with osubstituted aminoaromatics. Beckmann rearrangement of o-acylphenol oximes ${ }^{21}$ and photocyclization of phenolic Schiff bases also produce these componds ${ }^{22}$. Synthetic routes that are common to the preparation of these heterocycles typically involve the reaction of a carboxylic acid or its derivatives with an appropriate 1,2-phenylenediamine, 2-aminophenol or 2aminothiophenol in the presence of a strong acid at elevated temperatures ${ }^{23-24}$. Alternatively, a two-step procedure is employed wherein the 1,2- phenylenediamine, 2-aminophenol or 2 aminothiophenol is treated with one equivalent of an acid chloride, and the resulting mono Nacylated product is subjected to cyclodehydration under a variety of conditions such as heating in aqueous acids, ${ }^{25}$ by pyrolysis at $200-350{ }^{\circ} \mathrm{C}^{26-27}$ etc. In addition to the harsh conditions employed in these cases, some side reactions such as Friedel-Crafts acylation ${ }^{28}$ and Fries rearrangement ${ }^{29}$ also take place leading to lowering of selectivities. 


\section{Results and Discussion}

However, some of these methods suffer from one or more of the following drawbacks such as strong acidic conditions, long reaction times, low yields of the products, tedious work-up, need to use excess amounts of reagent and the use of toxic reagents, catalysts and solvents. Therefore, there is a strong demand for a highly efficient and environmentally benign method for the synthesis of these heterocycles. In recent years, studies of low-waste routes and reusable reaction media for enhanced selectivity and energy minimization have occupied the interests of synthetic organic chemists. ${ }^{30}$ In this context, the use of ionic liquids (ILs) as 'green' solvents in organic synthetic processes has gained considerable importance due to their solvating ability, negligible vapor pressure, and easy recyclability. They have the potential to be highly polar yet noncoordinating. In addition to the above-mentioned salient features of ILs as reaction media, they have also been shown to promote and catalyze organic transformations of commercial importance under ambient conditions. Recently, several synthetically useful organic transformations using this $\left[(\mathrm{bmim}) \mathrm{BF}_{4}\right]$ have been reported in the literature including oxidation of alcohols, acylation of alcohols, phenols, amines and thiols, esterification of long chain aliphatic carboxylic acids and alcohols, Michael addition of amines and indoles to $\alpha \beta$ unsaturated compounds. ${ }^{31}$

We wish to report, a novel regioselective one-pot synthesis of 2-aryl benzimidazoles, benzoxazoles and benzthiazoles in excellent yields promoted by imidazolium based ionic liquid [(bmim) $\left.\mathrm{BF}_{4}\right]$ under ambient conditions at higher temperature. In all cases, the IL could be recovered almost completely and recycled many times with only marginal losses in (2-3\%). It is interesting to note that all these reactions proceed to completion under ambient conditions in IL without any catalyst. The respective 2-aryl benzimidazoles, benzoxazoles and benzthiazoles were obtained in high regioselectivity and could be isolated in excellent yields in all cases.

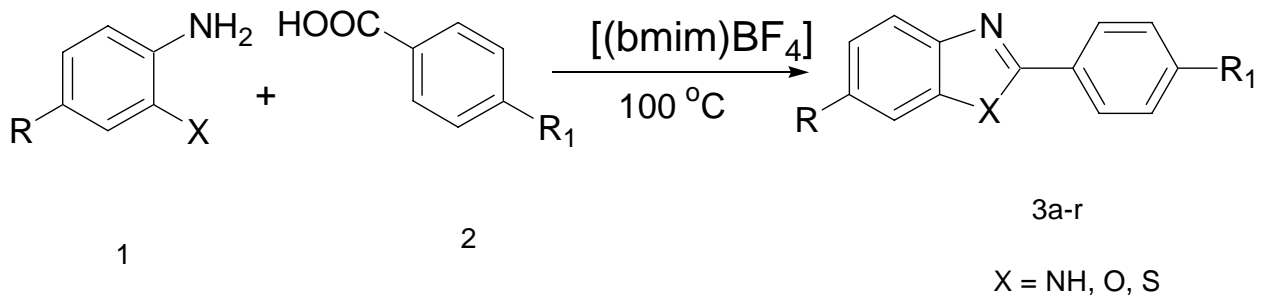


Table1. Synthesis of benzoxazoles, benzthiazoles and benzimidazoles from carboxylic acids

\begin{tabular}{ccccccc}
\hline S. No & Product 3 & $\mathrm{X}$ & $\mathrm{R}$ & $\mathrm{R}_{1}$ & $\begin{array}{c}\text { Time } \\
(\mathrm{min})\end{array}$ & $\begin{array}{c}\text { Yield } \\
(\%)\end{array}$ \\
\hline 1 & $3 \mathrm{a}$ & $\mathrm{NH}$ & $\mathrm{H}$ & $\mathrm{H}$ & 90 & 95 \\
2 & $3 \mathrm{~b}$ & $\mathrm{NH}$ & $\mathrm{H}$ & $\mathrm{Cl}$ & 90 & 91 \\
3 & $3 \mathrm{c}$ & $\mathrm{NH}$ & $\mathrm{H}$ & $\mathrm{Br}$ & 90 & 93 \\
4 & $3 \mathrm{~d}$ & $\mathrm{NH}$ & $\mathrm{H}$ & $\mathrm{CN}$ & 120 & 82 \\
5 & $3 \mathrm{e}$ & $\mathrm{NH}$ & $\mathrm{H}$ & $\mathrm{NO}_{2}$ & 120 & 80 \\
6 & $3 \mathrm{f}$ & $\mathrm{NH}$ & $\mathrm{H}$ & $\mathrm{OCH}_{3}$ & 90 & 96 \\
7 & $3 \mathrm{~g}$ & $\mathrm{O}$ & $\mathrm{H}$ & $\mathrm{H}$ & 90 & 93 \\
8 & $3 \mathrm{~h}$ & $\mathrm{O}$ & $\mathrm{H}$ & $\mathrm{Cl}$ & 90 & 89 \\
9 & $3 \mathrm{i}$ & $\mathrm{O}$ & $\mathrm{H}$ & $\mathrm{NO}_{2}$ & 120 & 81 \\
10 & $3 \mathrm{j}$ & $\mathrm{O}$ & $\mathrm{H}$ & $\mathrm{CN}$ & 120 & 79 \\
11 & $3 \mathrm{k}$ & $\mathrm{O}$ & $\mathrm{H}$ & $\mathrm{OCH}_{3}$ & 60 & 92 \\
12 & 31 & $\mathrm{O}$ & $\mathrm{H}$ & $\mathrm{Cl}^{2}$ & 90 & 90 \\
13 & $3 \mathrm{~m}$ & $\mathrm{~S}$ & $\mathrm{H}$ & $\mathrm{H}^{2}$ & 60 & 94 \\
14 & $3 \mathrm{n}$ & $\mathrm{S}$ & $\mathrm{H}$ & $\mathrm{NO}_{2}$ & 120 & 80 \\
15 & $3 \mathrm{o}$ & $\mathrm{S}$ & $\mathrm{OCH}$ & $\mathrm{CH}_{3}$ & 90 & 94 \\
16 & $3 \mathrm{p}$ & $\mathrm{S}$ & $\mathrm{OCH}$ & $\mathrm{NO}_{2}$ & 120 & 89 \\
17 & $3 \mathrm{q}$ & $\mathrm{S}$ & $\mathrm{H}$ & $\mathrm{CN}_{3}$ & 120 & 79 \\
18 & $3 \mathrm{r}$ & $\mathrm{S}$ & $\mathrm{H}$ & $\mathrm{OCH}_{3}$ & 90 & 96 \\
\hline & & & & & &
\end{tabular}

\section{Experimental Section}

General Procedures. NMR spectra were recorded on Bruker AC-300 spectrometer in $\mathrm{CDCl}_{3}$ with TMS as an internal standard. Mass spectra were obtained with Finnegan MAT mass spectrometer. Melting points were recorded in open capillary and were uncorrected. Column chromatography was performed using silica-gel (60-120 mesh size) purchased from Thomas Baker and TLC was carried out using aluminium sheets pre-coated with silica gel 60F254 purchased from Merck. All the solvents and chemicals used were reagent grade procured from Merck and Lancaster and used without further purification unless otherwise stated.

\section{Synthesis of heterocycles $3 a-3 r$}

The 2-aryl benzimidazoles, benzoxazoles and benzthiazoles were prepared as per the typical procedure described below for 6-methoxy-2-(4-nitro-phenyl)-benzothiazole (3p) in [bmim]BF .

Typical procedure for synthesis of for 6-Methoxy-2-(4-nitro-phenyl)-benzothiazole(3a) in [bmim]BF 4

A mixture of 2-amino-5-methoxy-benzenethiol (4.6 mmol) and 4-nitro-benzoic acid (4.6 mmol) in $[\mathrm{bmim}] \mathrm{BF}_{4}(4.6 \mathrm{mmol})$ was stirred at $100{ }^{\circ} \mathrm{C}$ temperature. The completion of reaction was 
followed by TLC using 35\% EtOAc in petroleum ether. After completion (10 min), the reaction mixture was diluted with water $(25 \mathrm{ml})$ and the separated product was filtered. It was washed thoroughly with water and dried. The product, thus isolated, was pure enough (single spot on TLC). It was subjected to further purification by chromatography through a column of silica-gel using $20 \%$ EtOAc in petroleum ether as eluent and was fully characterized. The aqueous layer consisting of the IL was subjected to distillation $\left(80{ }^{\circ} \mathrm{C}\right.$ at $10 \mathrm{mmHg}$ ) for $2 \mathrm{~h}$. Water was removed leaving behind the IL [bmim]BF 4 . M.p. $214-216{ }^{\circ} \mathrm{C}$ (lit. m.p ${ }^{32} 216-217{ }^{\circ} \mathrm{C}$ ); ${ }^{1} \mathrm{H}$ NMR $\left(\mathrm{CDCl}_{3}\right) \delta 3.91(\mathrm{~s}, 3 \mathrm{H}), 7.11(\mathrm{dd}, 1 \mathrm{H}, J=9.06 \mathrm{~Hz}), 7.35(\mathrm{~d}, 1 \mathrm{H}, J=2.26 \mathrm{~Hz}), 7.97(\mathrm{~d}, 1 \mathrm{H}, J=$ $9.06 \mathrm{~Hz}), 8.19-8.24(\mathrm{~m}, 2 \mathrm{H}), 8.31-8.36(\mathrm{~m}, 2 \mathrm{H}) . \mathrm{MS}(\mathrm{EI}): \mathrm{m} / \mathrm{z}(\%)=286\left(\mathrm{M}^{+}, 100\right), 271(32)$, 240 (28), 225 (30), 197 (30). Anal. Calcd for $\mathrm{C}_{14} \mathrm{H}_{10} \mathrm{~N}_{2} \mathrm{O}_{3} \mathrm{~S}: \mathrm{C}, 58.73 ; \mathrm{H}, 3.52 ; \mathrm{N}, 9.78 ; \mathrm{S}, 11.20$. Found: C, 58.69; H, 3.51; N, 9.73; S, 11.18 .

\section{Conclusions}

A one-pot regioselective synthesis of 2-aryl benzimidazoles, benzoxazoles and benzthiazoles in excellent yields has been developed under ambient conditions using room temperature ionic liquid as reaction medium and promoter. There is no need to add any catalyst, which is generally required in the methodologies reported so far. The ambient reaction conditions, absence of a catalyst and recyclability of the non-volatile ILs makes this an environment friendly methodology amenable for scale up.

\section{Acknowledgements}

One of the authors M. Amaravathi gratefully acknowledges Department of Science and Technology New Delhi, India for sanctioning women scientist scheme-A. We also thank National Institute of Technology Warangal India for providing lab facilities.

\section{References}

1. Denny, W. A.; Rewcastle, G. W.; Baguley, B. J. Med. Chem. 1990, 33, 814.

2. Kondo, J.; Suzuki, N.; Imaoka,T.; Kawasaki,T.; Nakanishi, A.; Kawahara, Y. Anal. Sci. 1994, 10, 17.

3. Zhao, M.; Samoc, M; Prasad, P. N.; Reinhardt, B. A.; Sinky, M. Chem. Mater. 1992, 2, 670.

4. Cassidy, P. E.; Thermally Stable Polymers, Marcel Dekker: New York, 1980.

5. Frachy, G.; Crestini, C.; Berini, R.; Salidino, R.; Micione, E. Heterocycles 1994, 38, 2621.

6. Song, X.; Vig, B. S.; Lorenzi, P. L.; Drach, J. C.; Townsend, L. B.; Amidon, G. L. J. Med. Chem. 2005, 48, 1274. 
7. Yildiz-Oren, I.; Yalcin, I.; Aki-Sener, E.; Carturk, N. Eur. J. Med. Chem. 2004, 39, 291.

8. Yamato, M. J. Pharm. Soc. Jpn. 1992, 112, 81.

9. Benazzouz, A.; Boraud, T.; Dubédat, P.; Boireau, A.; Stutzmann, J.-M.; Gross, C. Eur. J. Pharmacol. 1995, 284, 299.

10. Kumar, D.; Jacob, M. R.; Reynolds, M. B.; Kerwin, S. M. Bioorg. Med. Chem. 2002, 10, 3997.

11. Evans, D. A.; Sacks, C. E.; Kleschick, W. A.; Taber, T. R. J. Am. Chem. Soc. 1979, 101, 6789.

12. Figge, A.; Altenbach, H. J.; Brauer, D. J.; Tielmann, P. Tetrahedron: Asymmetry 2002, 13, 137.

13. So, Y. H.; Heeschen, J. P. J. Org. Chem. 1997, 62, 3552.

14. Villemin, D.; Hammadi, M.; Martin, B. Synth. Commun. 1996, 26, 2895.

15. Doise, M.; Dennin, F.; Blondeau, D.; Sliwa, H. Tetrahedron Lett. 1990, 31, 1155.

16. Jenkins, G. L.; Knevel, A. M.; Davis, C. S. J. Org. Chem. 1961, $26,274$.

17. Hein, D. W.; Alheim, R. J.; Leavitt, J. J. Am. Chem. Soc. 1957, 79, 427.

18. Terashima, M.; Ishii, M. Synthesis 1982, 484.

19. Salehi, P.; Dabiri, M.; Zolfigol, M. A.; Otokesh, S.; Baghbanzadeh, M. Tetrahedron Lett. 2006, 472557.

20. Chakraborti, A. K.; Rudrawar, S.; Kaur, G.; Sharma, L. Synlett 2004, 1533.

21. Bhawal, B. M.; Mayabhate, S. P.; Likhite, A. P.; Deshmukh, A. R. Synth. Commun. 1995, 25, 3315.

22. Chen, Y.; Zeng, D. X. J. Org. Chem. 2004, 69, 5037.

23. Preston, P. N. In Benzimidazoles and Congeneric Tricyclic Compounds. Part 1. The Chemistry of Heterocyclic Compounds, Wiessberger, A.; Taylor, E. C., Eds., Wiley: New York, 1981, p 5.

24. Terashima, M.; Ishii, M. Synthesis 1982, 1484

25. Philips, M. A. J. Chem. Soc. 1928, 2839.

26. Kudryashova, N.; Piotrovskii, L. B.; Naumov, V. A.; Brovtsyna, N. B.; Khromov-Borisov, N. V. Zh. Org. Khim. 1974, 10, 1542.

27. Ramana, D. V.; Kantharaj, E. Tetrahedron 1994, 50, 2485.

28. Tseitlin, G. M.; Tokarev, B. V.; Kulagin, V. N. Zh. Org. Khim. 1982, 18, 931.

29. Kanaoka, Y.; Hamada, T.; Yonemistu, O. Chem. Pharm. Bull. 1970, 18, 587.

30. Welton, T. Chem. Rev. 1999, 99, 2071.

31. Jain, N.; Kumar, A.; Chauhan, S.; Chauhan, S. M. S. Tetrahedron 2005, 61, 1015.

32. Andrea, I. P.; Valentina, T.; Curtis, H.; Sheo, S. S.; Jane, B.; Trepel, M.; Stevens, T.; Bradshaw, D.; Edward, A. S. J. Med. Chem. 1996, 39, 3375 